\title{
Measuring Empathy: Reliability and Validity of Empathy Quotient
}

\author{
Sreehari. $\mathrm{R}^{1 *}$, Joseph Thomas $\mathrm{R}^{2}$, Dr. Balan Rathakrishnan ${ }^{3}$, Daisy P.J ${ }^{4}$
}

\section{ABSTRACT}

The Empathy Quotient is a self-reported test to measure the cognitive and affective aspects of empathy. The purpose of this study was to develop a short version of Empathy Quotient and to establish its psychometric properties. The short version of empathy assessment scale and its correspondence with life skills assessment scale and social skills scale were evaluated in a sample of 971 school adolescents. A test-retest study was conducted at 2 weeks' time on a selected sample of 120 subjects from the original sample. Correlation and factor analyses were conducted. Result of the study indicates that the test-retest reliability was good, and the internal consistency was acceptable (Cronbach's alpha=0.65). Positive correlations were found between the empathy scale and other measures. In conclusion, Empathy scale showed acceptable psychometric properties and can be used in scientific studies.

Keywords: Reliability, Validity, Empathy, Empathy Quotient

Empathy has many meanings. It can be defined as the ability "to perceive the internal frame of reference of another with accuracy and with the emotional components and meanings which pertain thereto as if one were the person, but without ever losing the 'as if' condition" (Rogers, 1975) or "our ability to identify what someone else is thinking and feeling, and to respond to their thoughts and feelings with an appropriate emotion" (Baron-Cohen, 2001). Empathy is essential component in understanding social behavior. It allows us to understand the intentions of others, predict their behavior, and experience emotions triggered by their emotions (Kim.Et.al, 2010). Empathy is a prerequisite for social interaction. Indeed, empathic skills essential necessity for higher social functioning. There are three elements of empathy: 1) a cognitive capacity to take the perspective of the other person; 2) an effective response to another person that entails sharing that person's emotional state; and 3) certain regulatory mechanisms that keep track of the origins of self- and other-feelings (Kim \& Lee, 2010). Empathy is anessential capacity in everyday life. It is of great importance for teachers, psychologists and medical professionals,

\footnotetext{
${ }^{1}$ Assistant Professor, Tata Institute of Social Sciences, Mumbai, India

${ }^{2}$ Research Scholar, Rajiv Gandhi National Institute of Youth Development, Chennai

${ }^{3}$ Associate Professor, School of Psychology and Education, University Malaysia Sabah, Malaysia

${ }^{4}$ Assistant Professor, Department of Education, Assam Don Bosco University, Assam

*Responding Author

(C) 2016 I R Sreehari, J Thomas, B Rathakrishnan; licensee IJIP. This is an Open Access Research distributed under the terms of the Creative Commons Attribution License (http://creativecommons.org/licenses/by/2.0), which permits unrestricted use, distribution, and reproduction in any Medium, provided the original work is properly cited.
} 
students etc. Empathy is a central component of normal social functioning, providing a foundation for pro-social behavior (Charbonneau \& Nicol, 2002), maintaining social relationships (Noller \& Ruzzene, 1991), and enhancing psychological well-being (Musick \& Wilson, 2003). In view of this, the significance of being able to theorize and measure empathy seems clear-cut (Lawrence.E.J.et.al, Shaw, Baker, Baron-Cohen, \& David, 2004).

Empathy allows us to make sense of the behavior of others, predict what they might do next, how they feel and also feel connected to that other person, and respond appropriately to them (Wheelwright \& Baron-Cohen, 2011). The affective domain of empathy relates to an individual having an appropriate emotional response to the mental state of another. The cognitive domain is the ability to attribute mental states to others an understanding that other people have thoughts and feelings, and that these may not be the same as your own (Baron-Cohen, 1995).

There are several scales that have been developed to measure empathy but each this scales has its own advantages and limitations. The Questionnaire Measure of Emotional Empathy (Mehrabian \& Epstein, 1972) was aimed to assess emotional empathy. However, with hindsight, the authors suggest it may measure general emotional arousability instead (Mehrabian et al. 1988). The Balanced Emotional Empathy Scale (Mehrabian, 2000) measure reactions to others' mental states, but unfortunately, it are still not clear that they tap emotional empathy alone (Lawrence.E.J.et.al, 2004). Another scale measuring cognitive empathy (Hogan, 1969) was also developed in the 1960s; however critics also argue that it measures simply social skills rather than empathy per se (Davis, 1994).

\section{METHODOLOGY}

The purpose of this study was to develop a short version of Empathy Quotient and to establish its psychometric properties.

\section{Participants}

A sample of 971 school going adolescents (Male=484, Female=487) were selected using systematic random sampling procedure from five schools from randomly chosen locality in Kerala. In the second phase of the research, a sample of 120 adolescents was taken from the above sample for the test retest.

\section{Measures}

\section{Empathy Quotient developed by the Researchers.}

The Empathy scale was designed to be short, easy to use, and easy to score. This scale had 5 items in the form of statements with a 5 point scale for the respondents to rate. It is a self-reporting scale with positive and negative items. Sum of the total items will provide the score for empathy Quotient.

\section{Life skills Assessment Scale, Nair.et.al, 2014.}

This multi-dimensional Life skills assessment scale consists of 100 items in the form of statements in built with a 5 point scale for the respondent to check the appropriate response which is most descriptive of him/her. It has both positive and negative items. The 
scale measures 10 dimensions of life skills such as Self-awareness, Empathy, Effective Communication, Interpersonal Relationship, Creative thinking, Critical Thinking, Decision making, Problem solving, Coping with emotions and Coping with stress. The added advantage is that the scale could be self-administered or could be utilized in a group situation. The Life skills assessment scale is a self-administration scale. And it is based on the five point scale ranging from Always true of me to Not at all true of me. It has both positive and negative items. The reverse score is carried out for the negative items. The total of each dimension score indicates the raw score of the respective dimension. The sum of all the scores obtained under each of the 10 dimensions would evolve the Global Score of life skills

\section{Social Skills Scale , Ravindranath.et.al, 2015}

This is a 5 dimensional scale with 32 items. The dimensions of the scale are Selfawareness, Empathy, and Effective Communication and Interpersonal relationship. This scale has demonstrated good inter item and test-retest reliability, and convergent validity is indicated by correlations with other established scales.

\section{Procedure}

All participants completed the empathy quotient along with other measures. For each questionnaire, participants were instructed to read each statement carefully and judge how strongly they agreed or disagreed by selecting the appropriate option of each item

\section{RESULTS}

\section{Demographic Characteristics}

The socio-demographic profile of the students (Table-1) revealed that 50.2\% students were girls and $49.8 \%$ were boys. Most of the students belong to the age below 16yrs. Majority (45.8\%) of the students were Christian. With regard to the geographical location, $75.8 \%$ of the students were from rural locality. With regard to standard of study, $21.4 \%$ of the students were from 8th standard, $21.6 \%$ were from 9th standard and $13.7 \%$ were from 1oth standard. Only .5\% were from $11^{\text {th }}$ standard and remaining $42.7 \%$ were from 12 th standard.

\begin{tabular}{|l|l|l|}
\hline $\begin{array}{l}\text { Socio demographic } \\
\text { Variables }\end{array}$ & Frequency & Percentage \\
\hline Sex & & \\
\hline Boys & 484 & 49.8 \\
\hline Girls & 487 & 50.2 \\
\hline Age & & \\
\hline Below 14 yrs & 367 & 37.8 \\
\hline $14-16$ yrs & 360 & 37.1 \\
\hline Above 16 yrs & 244 & 25.1 \\
\hline
\end{tabular}




\begin{tabular}{|l|l|l|}
\hline Class & & \\
\hline $8^{\text {th }}$ Std & 208 & 21.4 \\
\hline $9^{\text {th }}$ Std & 210 & 21.6 \\
\hline $10^{\text {th }}$ Std & 133 & 13.7 \\
\hline $11^{\text {th }}$ Std & 5 & 0.5 \\
\hline $12^{\text {th }}$ Std & 415 & 42.7 \\
\hline Religion & & \\
\hline Hindu & 422 & 43.5 \\
\hline Muslim & 104 & 10.7 \\
\hline Christian & 445 & 45.8 \\
\hline Geographical Location & & \\
\hline Rural & 736 & 75.8 \\
\hline Urban & 235 & 24.2 \\
\hline
\end{tabular}

\section{Reliability}

Extensive data were collected to establish reliability and validity for empathy Scale. Using Cronbach's coefficient alpha, test retest, split half reliability methods the internal consistency was assessed for the tool. Using Cronbach's coefficient alpha, reliability was assessed on the scale remaining after item analysis and construct validity assessment. The test items showing weak indicators were eliminated in a stepwise fashion until the reliability coefficient peaked. However, highest reliability was already obtained without eliminating items. The final scale had a Cronbach's alpha coefficient of .65.

Table-2: - indicates the reliability Coefficients for Empathy scale

\begin{tabular}{|l|l|}
\hline Type of Coefficient & Reliability \\
\hline Test Retest & .71 \\
\hline Cronbach's Alpha & .65 \\
\hline
\end{tabular}

Measurement of reliability is another important part of standardization process of scale. Two types of reliability were established for the present scale. The internal consistency Cronbach's alpha has already been established based on the data of field-testing study. Apart from this test retest reliability coefficients were calculated using following procedure, Test Retest Reliability: The scale was administered after 2 weeks interval on the sample of 120 school adolescents considered for establishing the test retest reliability of the scale

\section{Validly Testing}

Concurrent Validity:

Concurrent validity examines the relationship of instrument with an outside criterion. Good concurrent validity indicated by good 'agreement' between a questionnaire or items score measuring same construct in the same units of measurement (Nunnally\& Bernstein 1994). 
Concurrent validity of the present scale was established on a sample of 120 school adolescents by comparing the scores of the empathy Scale (LSS) with other measures like Life Skills Assessment Scale and Social Skills scale.

\begin{tabular}{|l|l|l|l|l|l|l|l|}
\hline Variable & & Empathy & $\begin{array}{l}\text { Self- } \\
\text { awareness }\end{array}$ & $\begin{array}{l}\text { Effective } \\
\text { Communication }\end{array}$ & $\begin{array}{l}\text { Interpersonal } \\
\text { relationship }\end{array}$ & $\begin{array}{l}\text { Social } \\
\text { Skills }\end{array}$ & $\begin{array}{l}\text { Total } \\
\text { Life } \\
\text { Skills }\end{array}$ \\
\hline \multirow{2}{*}{ Empathy } & $\begin{array}{l}\text { Pearson } \\
\text { Correlation }\end{array}$ & $.812^{* *}$ & $.431^{* *}$ & $.518^{* *}$ & $.467^{* *}$ & $.757^{* *}$ & $.585^{* *}$ \\
\cline { 2 - 8 } & $\begin{array}{l}\text { Sig. } \\
(2 \text {-tailed) }\end{array}$ & .000 & .000 & .000 & .000 & .000 & .000 \\
\cline { 2 - 9 } & $\mathrm{N}$ & 120 & 120 & 120 & 120 & 120 & 120 \\
\hline
\end{tabular}

**. Correlation is significant at the 0.01 level (2-tailed).

The results of Pearson product-moment correlation revealed that score of empathy was positively correlated (Empathy: $\mathrm{r}=0.507, \quad \mathrm{p}<0.05$; Self Awareness: $\mathrm{r}=0.431, \mathrm{P}<0.05$; Effective Communication: $r=0.518, \mathrm{P}<0.05$, Interpersonal Relationship: $\mathrm{r}=0.467$ ) with all the dimensions of social skills and the total score of social skills $(r=0.757, \mathrm{P}<0.05)$. Significant correlation was established with empathy and overall score of life skills $(r=0.585, p<0.05)$ also.

\section{Factor Analysis}

A PCA with a varimax rotation showed the one factor. Factors were kept as it was apparent from both the scree plot and eigen values that they were the strongest, accounting for $36.57 \%$ of the total variance. The item loading for these single factors in the rotated solution are shown in Table 3. The Keiser-Meyer- Olkin measure of sampling adequacy was 0. 696 and the Bartlett test of sphericity were highly significant, suggesting the data were suitable for PCA. Factor 1 was labeled 'empathy'.

Table 3 Final loadings from principal components analysis

\begin{tabular}{|l|l|}
\hline Items & Component \\
\hline EM 1 & .670 \\
\hline EM 2 & .624 \\
\hline EM 3 & .607 \\
\hline EM 4 & .595 \\
\hline EM 5 & .517 \\
\hline
\end{tabular}

\section{Extraction Method: PCA}

\section{DISCUSSION}

The purpose of this study was to standardize a scale to assess the level of empathy among adolescents. The initial psychometric properties suggest that the Scale is a potentially reliable and valid measure of assessing empathy among adolescents. Good reliability was established for 
the scale where Cronbach's Alpha is around 0.65. The test retest score was also high which makes the scale more reliable. Empathy scale was shown to have concurrent validity as evident from the positive correlations with social skills and life skills assessment scale. Although the main limitation of the study is that total number of items in the scale which is considered too short for a standardized scale. But this limitation can be overcome by standardizing the scale in different population again. It will need further investigation in different populations. In conclusion, Empathy scale showed acceptable psychometric properties and can be used in scientific studies.

\section{REFERENCES}

Allison, C., Baron-Cohen, S., Wheelwright, S.J., Stone, M.H., \&Muncer, S.J. (2011). Psychometric analysis of the Empathy Quotient (EQ). Personality and Individual Differences, 51, 829-835.

Baron-Cohen, S. (1995). Mindblindness: An essay on autism and theory of mind. Boston: MIT Press/Bradford Books.

Baron-Cohen, S., Wheelwright, S., Hill, J., Raste, Y., \& Plumb, I. (2001). The "'Reading the Mind in the Eyes" test revised version: A study with normal adults, and adults with Asperger syndrome or high-functioning autism. Journal of Child Psychology and Psychiatry, 42(2), 241-251.

Charbonneau, D., \&Nicol, A.A.M. (2002). Emotional intelligence and prosocial behaviors in adolescents. Psychological Reports, 90, 361-370

Davis, M. H. (1994). Empathy : A Social Psychological Approach. Brown \& Benchmark: Dubuque, IA.

Hogan, R. (1969). Development of an empathy scale. Journal of Consulting and Clinical Psychology 33, 307-316.

Kim, J., \& Lee, S. J. (2010). Reliability and Validity of the Korean Version of the Empathy Quotient Scale. Psychiatry Investigation, 7(1), 24-30.

Lawrence, E.J., Shaw, P., Baker, D., Baron-Cohen, S., \& David, A.S. (2004). Measuring empathy: Reliability and validity of the Empathy Quotient. Psychological Medicine, 34, 911-919

Mehrabian, A., \& Epstein, N. (1972). A measure of emotional empathy. Journal of Personality, 40, 525-543.

Mehrabian, A., Young, A. L. \& Sato, S. (1988). Emotional empathy and associated individual differences. Current Psychology : Research \& Reviews 7, 221-240

Musick, M.A., \& Wilson, J. (2003). Volunteering and depression: The role of psychological and social resources in different age groups. Social Science \& Medicine, 56, 259-269.

Noller, P., \& Ruzzene, M. (1991). Communication in marriage: The influence of affect and cognition. In G.J.O. Fletcher \& F.D. Fincham (Eds.), Cognitions in close relationships (pp. 203-233). Hillsdale, NJ: Erlbaum.

Nunnally, J.C. \& Bernstein, I.H. (1994) Psychometric theory. New York: McGraw Hill Books Inc. 
Rogers, C.R. (1975). Empathic: An unappreciated way of being. The Counseling Psychologist, 5, 2-10.

Wakabayashi, A., Baron-Cohen, S., Wheelwright, S., Goldenfeld, N., Delaney, J., Fine, D., Smith, R., and Weil, L. (2006). Development of short forms of the empathy quotient (eqshort) and the systemizing quotient (sq-short). Personality and Individual Differences, 41:929-940.

Wheelwright, S., \& Baron-Cohen, S. (2011). Systemising and Empathising. In D. A. Fein (Ed.), The neuropsychology of autism.

How to cite this article: R Sreehari, J Thomas, B Rathakrishnan (2016), Measuring Empathy: Reliability and Validity of Empathy Quotient, International Journal of Indian Psychology, Volume 3, Issue 3, No. 7, DIP: 18.01.132/20160303, ISBN: 978-1-365-12175-3 